\title{
Ambiência no atendimento de crianças e adolescentes em um CAPSi
}

The ambience of children and adolescent care service at a CAPSi

Contexto ambiental en la atención de niños y adolescentes en un CAPSi

\author{
Juliana Peterle Ronchi* \\ Luziane Zacché Avellar *
}

\begin{abstract}
Resumo
A ambiência como um dos aspectos da política de humanização do Sistema Único de Saúde (SUS) apresenta a importância de se atentar à arquitetura dos serviços de saúde, uma vez que podem produzir formas de cuidar. O objetivo deste trabalho foi conhecer e descrever a ambiência no atendimento de crianças e adolescentes com transtornos mentais graves em um Centro de Atenção Psicossocial Infantojuvenil (CAPSi), priorizando os aspectos físicos desse conceito. Esta pesquisa de caráter clínico-qualitativa foi realizada em um CAPSi. Como procedimento de coleta de dados, utilizou-se da técnica da observação participante. Os resultados evidenciaram que as constituições espaciais de um serviço de saúde podem influenciar suas práticas, pois se verificou que, em alguns momentos, a ambiência do CAPSi, em seus elementos físicos, possibilitava comunicaçōes significativas de crianças e adolescentes.
\end{abstract}

Palavras-chave: Serviços de saúde mental. Crianças. Adolescentes.

\begin{abstract}
Ambience as one of the aspects of the Brazilian Unified Health System humanization policy shows the importance of paying attention to architecture of health care service units. This study aimed at understanding and describing the ambience of health care services for children and adolescents with severe mental disorders at CAPSi, focusing on the physical aspects of this concept. This clinical-qualitative study was carried out at the CAPSi - Children and Youth Psychosocial Care. Data collection employed the participant
\end{abstract}

\footnotetext{
Texto recebido em maio 2014 e aprovado para publicação em janeiro de 2015.

Este artigo faz parte da dissertação de mestrado apresentada ao Programa de Pós-Graduação em Psicologia (PPGP) da Universidade Federal do Espírito Santo (UFES), intitulada "Ambiência e saúde mental: um estudo no CAPSi de Vitória-ES", que recebeu apoio financeiro da Fundação Coordenação de Aperfeiçoamento de Pessoal de Nível Superior (CAPES). Mestra em Psicologia pelo Programa de Pós-Graduação em Psicologia (PPGP) da Universidade Federal do Espírito Santo (UFES), psicóloga do Instituto Federal de Educação, Ciência e Tecnologia do Espírito Santo (IFES). Endereço: Avenida Fernando Ferrari, 514, Vitória-ES, Brasil. CEP: 29075-910. E-mail: peterleronchi@yahoo.com.br.

* Professora doutora do Departamento de Psicologia Social e do Desenvolvimento (DPSD) e do Programa de Pós-Graduação em Psicologia (PPGP) da UFES, psicóloga. Endereço: Avenida Fernando Ferrari, 514, Vitória-ES, Brasil. CEP: 29075-910.

E-mail: luzianeavellar@yahoo.com.br.
} 
observation technique. The results showed that the spatial make - up of a health care service can influence this practice. The ambience at CAPSi, in its physical elements, occasionally enabled significant communication among children and adolescents.

Keywords: Mental health services. Children. Adolescents.

\section{Resumen}

El contexto ambiental como uno de los aspectos de la política de Humanización del Sistema Único de Salud (SUS) presenta la importancia de considerar la arquitectura de los servicios de salud una vez que pueden producir formas de cuidar. El objetivo de este trabajo fue conocer y describir el contexto ambiental en la atención de niños y adolescentes con trastornos mentales graves en el Centro de Atención Psicosocial InfantoJuvenil (CAPSi), dando prioridad a los aspectos físicos de ese concepto. Esta investigación de carácter clínico-cualitativa, ha sido realizada en un CAPSi y como procedimiento de recolección de datos se ha utilizado la técnica de la observación participante. Los resultados demostraron que las constituciones espaciales de un servicio de salud pueden influenciar sus prácticas, una vez que se ha verificado que en algunos momentos el contexto ambiental del CAPSi, en sus elementos físicos, posibilitaban comunicaciones significativas de niños y adolescentes.

Palabras clave: Servicios de salud mental. Niños. Adolescentes.

\section{Introdução}

N

o Brasil, o Ministério da Saúde redireciona o modelo de assistência em saúde mental a partir da Lei n. ${ }^{\circ}$ 10.216, de 6 de abril de 2001, e, de acordo com a Portaria n. ${ }^{\circ}$ 336, de 19 de fevereiro de 2002, institui o Centro de Atenção Psicossocial Infantojuvenil (CAPSi). Ligado ao Sistema Único de Saúde (SUS) e pertencente à gestão municipal, organiza-se como um ambulatório diário para crianças e adolescentes com transtornos mentais severos e persistentes, configurando-se como um modelo de atenção pautado em bases territoriais e comunitárias.

Embora promovendo avanços com a instituição do CAPSi, o Ministério da Saúde (MS) ratifica o desafio de se construir uma política de saúde mental para crianças e adolescentes, pois as especificidades de atendimento desse público devem ir além do modelo assistencial estruturado para os adultos (Brasil, 2005).

No contexto da Reforma Psiquiátrica, incluir o sujeito que sofre e reabilitá-lo socialmente são medidas prioritárias que devem estar contidas em um ambiente 
terapêutico de saúde mental. Prevenir doenças e promover saúde são as novas possibilidades apresentadas pelo SUS, para além da atuação curativista. Nesse contexto, a humanização como política do SUS amplia a compreensão do processo saúde-doença nos espaços dos serviços de saúde, problematizando a efetivação de diferentes práticas (Benevides \& Passos, 2005; Brasil, 2006b).

Integrando aspectos teóricos e práticos, a humanização traz em seu contexto a luta pelo direito à atenção e acolhida por parte dos usuários e o respeito às condições de trabalho dos profissionais. Um dos aspectos da política de humanização é a ambiência, definida como:

Ambiente físico, social, profissional e de relações interpessoais que deve estar relacionado a um projeto de saúde (confira-se: Projeto de saúde) voltado para a atenção acolhedora, resolutiva e humana. Nos serviços de saúde, a ambiência é marcada tanto pelas tecnologias médicas ali presentes quanto por outros componentes estéticos ou sensíveis apreendidos pelo olhar, olfato, audição, por exemplo, a luminosidade e os ruídos do ambiente, a temperatura, etc. Muito importante na ambiência é o componente afetivo expresso na forma do acolhimento, da atenção dispensada ao usuário, da interação entre os trabalhadores e gestores. Devem-se destacar também os componentes culturais e regionais que determinam os valores do ambiente (Brasil, 2006a, p. 35, grifo do autor).

A ambiência facilita o engajamento do usuário, pois evidencia a importância do bem-estar do sujeito no ambiente em que fará seu tratamento de saúde. Nesse contexto, também é importante considerar os espaços de visita e de espera dos acompanhantes, ratificando o valor dos ambientes dos serviços de saúde como espaços que atendam, com conforto, às necessidades dos sujeitos, garantindo acolhimento e escuta não SOMENTE à pessoa que está doente, mas também aos que estão à sua volta, como os familiares, que, em geral, contribuem de modo significativo no tratamento de saúde. É fundamental considerar as atividades que o serviço desenvolve, de modo que o espaço em que esteja lotado seja adequado à efetividade de suas ações (Brasil, 2010).

Para Cohen, Bodstein, Kligerman e Marcondes (2007), a promoção da saúde no Brasil propóe o redirecionamento dos sistemas de serviços de saúde e de gestão ambiental. Compreender aspectos da ambiência em um determinado espaço mostra-se, para os autores, uma ação estratégica, dado que possibilita a construção de projetos de saúde com maior qualidade técnica, identificados com as necessidades da população a que se destinam.

A ambiência como um dos aspectos da política de humanização do SUS (BRASIL, 2006a) apresenta a importância de se atentar à arquitetura dos serviços 
de saúde como territórios de encontros, os quais devem considerar as situações em que as ações de saúde são construídas. A fim de agregar maior possibilidade de reflexão sobre a ambiência, empregaremos, neste estudo, o referencial teórico de Donald Woods Winnicott, pois esse autor enfatiza, em seus escritos, a importância do ambiente na estruturação psíquica da pessoa.

Para Winnicott (1952/2000), (1954/2000), (1956/2000), ${ }^{1}$ apenas um ambiente suficientemente bom possibilita ao bebê se desenvolver, pois provê adequadamente suas necessidades. $\mathrm{O}$ autor afirma que uma adequada provisão ambiental no início da infância previne estados que, no adulto, serão chamados de loucura.

Para Winnicott, uma boa ambiência deve fornecer cuidado e manejo adequados para que o bebê caminhe em direção à integração, personalização e estabeleça relações de objeto. $\mathrm{O}$ holding, o handling e a apresentação de objeto proveem condições para que o indivíduo se desenvolva.

Ao fornecer os cuidados iniciais de alimentação e higiene, a mãe segura (holding) de maneira confiável e manipula (handling) o corpo de seu bebê, possibilitando a ele ser em totalidade; nesse ambiente em que é significado e sustentado, o indivíduo se personaliza. A apresentação de objeto, por sua vez, proporciona a apresentação do mundo ao bebê de uma forma adequada em que gradativamente ele possa lidar com os elementos do contexto em que está inserido, o bebê se movimenta e vai ao encontro de um objeto que inicialmente é ele mesmo quem cria, e se o ambiente pode criar essa ilusão no bebê, de que o que ele necessita estará à sua disposição, então ele pode se desenvolver de modo saudável, relacionando-se com os objetos do mundo que o cerca, constituindo as separações eu/não eu (Winnicott, 1962/1983; Avellar, 2004).

Em uma situação de ambiente terapêutico, nessa perspectiva teórica, todos esses aspectos do processo maturacional devem ser fornecidos, a fim de facilitar o processo de amadurecimento emocional do paciente. Winnicott (1964/1994) postula que, para alguns pacientes, a provisão e a manutenção do setting são mais importantes do que o trabalho interpretativo. E, como afirma o autor, muitas vezes oferecer um setting adequado mostra-se um desafio.

Em um CAPSi, uma ambiência adequada, como apresenta o Ministério da Saúde (Brasil 2006a, 2010), possibilita um serviço acolhedor e confortável aos usuários. Nesses serviços, ainda, uma apropriada provisão ambiental, tal como a define Winnicott (1962), pode favorecer aos pacientes reviverem necessidades primitivas que, em um momento anterior, não foram satisfeitas, sendo agora acolhidas e cuidadas por uma equipe de profissionais. Dessa forma, o objetivo 1 A primeira data indica o ano de publicação original da obra, e a segunda indica a edição consultada pelo autor. Ambas serão pontuadas somente na primeira citação da obra no texto. Nas seguintes, será registrada apenas a original. 
deste trabalho foi conhecer e descrever a ambiência no atendimento de crianças e adolescentes com transtornos mentais graves em um Centro de Atenção Psicossocial Infantojuvenil, priorizando os aspectos físicos.

\section{Método}

Esta pesquisa de caráter clínico-qualitativa foi realizada em um CAPSi. De acordo com Turato (2003), o método de pesquisa clínico-qualitativa é uma particularização e um refinamento do método qualitativo que guarda especificidades de vertentes clínico-psicológicas, sendo adequado para descrever e compreender fenômenos constituídos nos settings de saúde.

Como procedimento de coleta de dados, usou-se a técnica da observação participante, que consiste na presença de um observador em contato direto com o fenômeno observado, a fim de colher dados do contexto, na realidade em que ocorre para a realização de uma investigação científica (Minayo, 1994).

Para Minayo (1994), a observação participante permite ao pesquisador entrar em contato direto com a realidade que deseja conhecer, na qual as informações são obtidas no próprio contexto em que ocorrem, tendo em vista que não podem ser apreendidas simplesmente por meio de falas ou da escrita, permitindo uma compreensão mais global da situação estudada.

Ainda, nos registros das observações realizadas no CAPSi, não foram descritos apenas os fenômenos observados, mas também a conversação estabelecida entre pesquisador, profissionais e usuários do serviço. Pois, como indica Becker (1997), o observador participante, além de ver as situaçóes no contexto em que ocorrem, estabelece conversações com os participantes dessas situações, descobrindo as interpretações sobre os acontecimentos observados, dadas pelos atores e autores do processo.

As observações seguiram um roteiro abrangendo os aspectos físicos do conceito de ambiência apresentado pelo Ministério da Saúde (Brasil, 2006a, 2010): constituição dos ambientes de atendimento, confortabilidade dos espaços, acessibilidade ao serviço e privacidade, descritos nos resultados. As visitas foram diárias, com duração de aproximadamente duas horas, intercaladas entre um dia na parte da manhã e um dia na parte da tarde, isso porque se verificou que a rotina era diferente por causa dos pacientes e da equipe, que se distinguia por dias e turnos. Desse modo, pretendeu-se observar diversos contextos da ambiência do CAPSi. Foi utilizado o critério de saturação das informações, de modo que, ao final de três meses, verificou-se um grau de repetição nas observações, indicando que os dados coletados se mostravam suficientes para os propósitos da pesquisa. 
Assim, foram 143 horas de observação, de março a junho de 2011.

Todas as observaçôes realizadas na instituição foram registradas, gerando diário de campo, elemento essencial do pesquisador, quando se utiliza de observação participante. O registro das informações foi feito logo após as observações realizadas, no próprio CAPSi, em locais onde não havia atividades.

Utilizou-se, para a análise de dados, uma particularização e refinamento da técnica de análise de conteúdo, como propóe Turato (2003), visando às características do método clínico-qualitativo.

Em um primeiro momento, Turato (2003) afirma que se devem organizar as informações coletadas. Em nosso caso, conforme a pesquisa se realizava, nosso material se configurava, uma vez que, a cada dia, logo a após a observação, no próprio CAPSi, o registro das observaçôes era realizado. Assim, no último dia de coleta de dados, o diário de campo estava constituído, em sua íntegra, de forma organizada. No segundo momento, realizou-se a leitura flutuante do diário de campo, a fim de o pesquisador familiarizar-se com os dados coletados como um todo. No terceiro momento, selecionaram-se do material coletado, os dados originais, os elementos mais relevantes para responder aos objetivos do estudo. Finalizando, realizou-se a redação do trabalho com descrições do fenômeno investigado, de acordo com os dados coletados e sua interpretação, o que acrescentou à descrição elementos teóricos que possibilitaram maior reflexão sobre o material organizado.

Como afirma Avellar (2009), a seleção do material de pesquisa impõe:

[...] uma certa descontinuidade, certos recortes e espaços vazios que, certamente, possuem seus significados, pelos quais, muitas vezes, passa-se por cima, a fim de realizar uma redução dos elementos apresentados. Em alguns casos, há perdas difíceis de serem reparadas. É um risco que se corre. (p. 16).

D’Allones (2004), baseando-se em Levi Strauss, afirma que, em muitos casos, não se trata de perda do material coletado, mas da construção do objeto de estudo de modo mais compreensivo. Recorrendo à bricolagem, D'Allones (2004) cita Levi Strauss, para quem o termo está desprovido de qualquer conotação pejorativa, uma vez que um problema pode ter várias soluçôes. A bricolagem, desse modo, apresenta a possibilidade de se reunir diferentes recortes sem rigidez alguma, produzindo um novo objeto de forma livre. 
Nesta pesquisa, correu-se o risco de selecionar, diante de uma grande quantidade de anotações, as que possibilitariam, ante a leitura do pesquisador, a compreensão da ambiência em um CAPSi. Apresenta-se, assim, pela configuração de uma bricolagem, utilizada na análise dos dados, o que se pensou, refletiu-se e se viveu em uma experiência de pesquisa que articula a interação pesquisadorpesquisados.

Para a interpretação dos dados, utilizou-se o referencial da teoria de Donald Woods Winnicott, pois, para esse autor, como apresentamos anteriormente, o ambiente tem papel fundamental na saúde psíquica da pessoa. Assim, espera-se ultrapassar a mera descrição dos fenômenos investigados, objetivando atingir uma interpretação mais profunda dos dados coletados.

O projeto de pesquisa foi apresentado à Secretaria Municipal de Saúde da Prefeitura à qual pertence o serviço, à diretora e à equipe do CAPSi, com a finalidade de informar-lhes acerca dos objetivos da pesquisa e de obter o consentimento para sua realização. Foi informado ainda que os resultados obtidos seriam apresentados em congressos e artigos científicos, sendo resguardada a confiabilidade dos dados. Esclareceu-se que não haveria divulgação de dados que pudessem identificar os usuários envolvidos no estudo (Resolução n. ${ }^{\circ}$ 196/1996). Uma vez que cumpria todas as exigências, obtivemos o consentimento para sua realização. Esta pesquisa obteve aprovação (n. $\left.{ }^{\circ} 226 / 10\right)$ no Comitê de Ética em Pesquisa do Centro de Ciências da Saúde da Universidade Federal do Espírito Santo.

\section{Resultados}

\section{A estrutura física do CAPSi}

Tendo como objetivo conhecer a ambiência em seus aspectos físicos, segue descrição de elementos do ambiente do CAPSi, para, em seguida, realizar-se a discussão.

O CAPSi investigado está vinculado à Secretaria Municipal de Saúde e funciona em uma casa alugada pela Prefeitura. A equipe do CAPSi é composta por profissionais de níveis superior, médio e técnico. $\mathrm{Na}$ época da pesquisa, o serviço contava com 4 psicólogos, 1 médico pediatra, 2 assistentes sociais, 2 arteterapeutas, 2 terapeutas ocupacionais, 1 musicoterapeuta, 2 enfermeiros, 4 técnicos de enfermagem, 1 educador físico, 2 assistentes administrativos, 4 vigilantes patrimoniais e 2 auxiliares de serviços gerais. $O$ horário de funcionamento era das $7 \mathrm{~h}$ as $19 \mathrm{~h}$. 
O CAPSi pesquisado apresenta uma recepção com sala de espera equipada com ar-condicionado, ventilador, televisão, som, jornais, revistas, brinquedos, lápis, papel, mesa e cadeiras apropriadas para as crianças e para os familiares utilizarem enquanto esperam o atendimento no serviço. $\mathrm{O}$ acesso dos usuários a bebedouro e banheiro é facilitado.

O serviço tem três salas de atendimento individual, com brinquedos, jogos, filmes infantis, fantasias infantis, fantoches, livros, papel e lápis de cor, revistas, tintas guache, livros de história e livros médicos, sendo que, em cada sala, há predominância de um desses itens, possibilitando o uso de acordo com o objetivo do atendimento. Também conta com uma enfermaria, uma sala de reuniōes, uma sala para a diretoria com banheiro, uma sala de artes com um repartimento à parte onde são guardados vários instrumentos musicais e banheiro, cozinha, almoxarifado, área de serviço, um banheiro para os profissionais e um banheiro para os pacientes e cuidadores, ambos com espelho.

Durante a coleta de dados, alguns elementos do espaço físico ainda estavam adaptando-se às necessidades do serviço, pois, com o aumento da procura por atendimento, o CAPSi foi transferido para a atual casa, em meados de 2010, a um quarteirão do antigo imóvel em que funcionava. Mais ampla do que a anterior, segundo os profissionais. $\mathrm{O}$ atual serviço tem varandas e um pátio interno com uma mesa que é utilizada para as oficinas e para as refeições, além de uma mesa de totó, cadeiras e mesa infantil, uma churrasqueira, árvores frutíferas, como jabuticabeira, mangueira, jambeiro e varandas com bancos para pacientes e familiares.

Durante a coleta de dados, iniciou-se a reforma da piscina, que também fica no pátio interno, cercada por grades com portão trancado e controlado pelos profissionais. A obra tem por objetivo adequar a profundidade da piscina para as crianças que utilizam o serviço. Embora visando à melhoria do serviço, as obras na piscina inviabilizaram por alguns dias as atividades no pátio interno por causa da poeira e do barulho.

Apenas no pátio interno e na sala de artes encontravam-se pinturas, colagens e desenhos das crianças e dos adolescentes, e, eventualmente, dos profissionais. No pátio interno, as atividades coladas nas paredes se renovam, os pacientes tiram ou colocam suas produções por conta própria; em alguns momentos, os profissionais os incentivam a exporem seus trabalhos. Na sala de espera, há cartazes informativos do Ministério da Saúde e das secretarias municipais de Saúde e Ação Social, além de informes gerais.

As composições dos espaços do CAPSi são diferentes para atender às diversas atividades desenvolvidas pelos profissionais, como atendimentos individuais ou 
em grupo, oficinas, brincadeiras e jogos. Os profissionais afirmam que, antes de realizarem a mudança para a atual casa, fizeram toda uma organização, definindo o que seria cada espaço, mas, quando mudaram efetivamente, adequaram os espaços à funcionalidade do serviço, modificando a estrutura que haviam pensado anteriormente à mudança.

Os atendimentos em grupo acontecem de modo mais frequente na varanda e no pátio interno com iluminação natural. Quando chove, os profissionais e os pacientes se organizam nas salas de atendimentos individuais, pois, para se chegar à sala de artes, que é ampla, precisa-se passar por espaços descobertos. Além disso, em dias de chuva, geralmente chegam poucas crianças e adolescentes ao serviço, tendo em vista o transporte utilizado, que, para a maioria das famílias, é o coletivo.

Os espaços do CAPSi são limpos, conservados, iluminados e possibilitam a privacidade nos atendimentos, cabendo aos profissionais escolher adequadamente os espaços para cada atividade. As salas para os atendimentos individuais e em grupo, por exemplo, têm as janelas em direção ao pátio interno, permanecendo fechadas durante os momentos de atendimentos individuais e abertas quando os atendimentos são em grupo e todos podem participar.

\section{Discussão}

Um primeiro aspecto para discussão é o fato de a casa em que se localiza o CAPSi ser alugada. Como afirma Demartini (2007), grande parte dos serviços de saúde no Brasil funcionam em residências alugadas pelos governos municipais ou estaduais. O CAPSi, por ser um serviço relativamente novo de saúde mental, não tem parâmetros que estabeleçam as características físicas dos ambientes em que devem funcionar, o que, de acordo com a autora, pode dificultar o tratamento dos pacientes e o trabalho dos profissionais.

Observou-se que o serviço oferecido pelo CAPSi precisou adequar-se às condições físicas ofertadas por uma casa, que, se por um lado, pode não oferecer as condições apropriadas para o funcionamento de um serviço de saúde mental, por outro, possibilita o uso de diferentes espaços físicos como promotores de saúde. Como afirma Souza (2003), o funcionamento de um Centro de Atenção Psicossocial (CAPS) em uma casa organiza a proposta de tratamento de forma completamente diferente das instituições asilares.

A sala de espera, com brinquedos, jornais, revistas e televisão para as crianças, os adolescentes e familiares, por exemplo, possibilita conforto enquanto aguardam o atendimento. Tomar uma água, utilizar o banheiro, ler ou assistir a reportagens 
ou às notícias do dia, com liberdade, possibilitam uma aproximação do uso do serviço de fato como uma casa, lugar aconchegante e acolhedor, produzindo intimidade dos usuários com a instituição de saúde. Como apresenta o texto do Ministério da Saúde (Brasil, 2010), o conforto deve ser priorizado não apenas para aqueles que utilizam o serviço, nesse caso as crianças e os adolescentes, mas deve se estender aos familiares, pois são pessoas fundamentais na adesão ao tratamento.

Na sala de espera, também se observou a interação entre crianças e adolescentes, que brincavam juntos enquanto aguardavam os atendimentos, e os familiares que, conversando, trocavam experiências sobre as facilidades e dificuldades do cotidiano. Os desenhos, as brincadeiras e as conversas produzidas na sala de espera mostravam-se boas oportunidades de intervenção.

Souza (2003), em sua dissertação de mestrado, apresenta-nos o termo "ambiência" como o nome dado a uma atividade realizada pelos profissionais de um CAPS, em que estes circulavam pelos espaços do serviço, a fim de intervir junto aos usuários fora das atividades previstas. Os profissionais nomearam e organizaram tal atividade na grade de tarefas do CAPS, pois perceberam que, nesses momentos, é possível conversar e conhecer melhor os usuários, fora dos padrōes dos atendimentos comuns, o que se revelou importante fonte de informações para a realização de novos projetos no CAPS. Souza (2003) apresenta que:

[...] uma das características mais interessantes da Ambiência é o fato de ela permitir a criação e invenção de projetos pessoais ou coletivos. Muitas vezes, algo que, por diversos motivos, não aparece num grupo ou em outro tipo atendimento, pode aparecer no banco do jardim ou em outro espaço. (p. 73)

Apesar de a definição de ambiência utilizada neste trabalho estar de acordo com o que definiu o Ministério da Saúde (Brasil, 2006a), sendo um espaço que visa à confortabilidade, à socialização entre os sujeitos, o atendimento humanizado, com espaços acolhedores e resolutivos e mostrar-se diferente da utilizada por Souza (2003), que a demarcou como o contato entre profissionais e usuários de um CAPS em espaços nos quais não havia, a princípio, uma atividade organizada, sendo uma tarefa do CAPS pesquisado.

Verificou-se como a circulação do profissional em um serviço de saúde pode ser importante em sua prática. Confirmando os achados da dissertação de Souza (2003), a ambiência de um serviço de saúde, se bem explorada, pode facilitar 
ao usuário a comunicação do seu sofrimento, abrindo a possibilidade para o trabalho terapêutico se realizar.

No entanto, como acentua Winnicott (1971/1984), a comunicação para que o trabalho terapêutico aconteça somente pode se tornar possível quando há um Outro capaz de compreender o sofrimento do sujeito. Winnicott evidencia, em sua teoria, que, para a criança desenvolver-se, é necessária a presença da mãe, que faz o papel do ambiente suficientemente bom, fornecendo as condições necessárias ao processo do amadurecimento. Usando dessa analogia, o autor postula que, em um tratamento terapêutico, a disposição do profissional deve ser como o da mãe, no sentido de acolher de maneira adequada as expressões dos pacientes, no caso do profissional, em um tempo e espaço limitados.

Hisada (2000) com o objetivo de verificar como uma adaptação ambiental (setting) favorece o desenvolvimento psíquico, evidencia que o setting em que acontece o trabalho terapêutico é a possibilidade de recuperação, pelo paciente, das funções relacionadas às primeiras etapas de seu desenvolvimento.

Para Khan (1984), o setting é definido como a ambiência física proporcionada pelo analista, sendo a configuração adequada às necessidades do paciente, como a mobília, a luz, a sala e a sua presença. Percebe-se que a definição utilizada por Massud Khan sobre o que é o setting coincide, em alguns aspectos, com o conceito de ambiência utilizado pelo Ministério da Saúde (Brasil, 2006a), como a mobília, a iluminação, o conforto e a privacidade dos espaços de atendimento. Dessa forma, o espaço físico do CAPSi, planejado para o atendimento de crianças e adolescentes, deve conter em si elementos que facilitem e proporcionem aos pacientes comunicar e elaborar seus conflitos psíquicos.

Nesse sentido, os materiais disponíveis no serviço, como jogos, brinquedos e instrumentos musicais favorecem a intervenção dos profissionais, pois possibilitam a comunicação com os pacientes por meios lúdicos. Algumas crianças e adolescentes que chegavam ao serviço com dificuldades de interagir com os profissionais logo faziam contato por intermédio dos instrumentos musicais, o que os acalmava e propiciava uma comunicação.

Como afirma Hisada (2000), "As associações verbais e pré-verbais podem ser entendidas e interpretadas por ocorrerem dentro do limite e da estrutura do setting" (p. 21, grifo do autor), que deve modificar-se e adaptar-se às necessidades do paciente. Para a autora, os símbolos e os elementos que compõem esse espaço são fundamentais, pois podem proporcionar aos pacientes familiaridades com o ambiente, facilitando o estabelecimento de comunicação. 
A aproximação do paciente com o serviço também se fazia pelas suas produçōes gráficas expostas no pátio interno. Em alguns momentos, as crianças e os adolescentes referiam-se ao seu trabalho (colagens, pinturas, desenhos), abrindo possibilidades ao diálogo e à construção de novos referenciais sobre suas ações. Os pacientes constatavam que poderiam produzir materiais em que se reconheciam, nos espaços em que circulavam. Dessa forma, percebeu-se como elementos do ambiente físico de um serviço de saúde podem se tornar meios de comunicação e interação entre pacientes e profissionais, possibilitando o desenvolvimento de intervenções adequadas.

Como salienta Safra (1999), os contornos do espaço e do tempo, os objetos e símbolos são importantes para que o ser humano possa viver e existir. Baseandose na teoria de Winnicott, o autor afirma que, por um ambiente favorável, o ser humano poderá constituir-se como pessoa, fazendo uso dos símbolos de sua cultura como elementos de significação de sua história pessoal. Dessa forma, as produções artísticas expostas nas paredes do CAPSi possibilitavam a identificação dos pacientes com o espaço e a apropriação de símbolos na construção e significação das suas histórias de vida.

O espaço físico do CAPSi e sua utilização privilegiavam ações ao ar livre, permitindo inclusive a exploração de atividades coletivas. Em dias de chuva, no entanto, havia restrição de atividades. A valorização excessiva dos espaços coletivos em detrimento dos espaços individuais, em alguns momentos, dificultava a privacidade das intervenções e colocações mais particularizadas.

Winnicott (1971) evidencia que:

[...] se é dada a oportunidade de maneira adequada e profissional para uma criança ou para um adulto, no tempo limitado do contato profissional o cliente trará e exporá (embora de início apenas como uma tentativa) o problema predominante ou o conflito emocional ou a espécie de tensão que aparece nesse momento da vida do cliente. (p. 15)

Para o autor, a presença profissional do analista, o tempo e o espaço limitados, ou seja, o setting marca para o cliente que "[...] a compreensão pode talvez ser acessível e que a comunicação a um nível profundo pode se tornar possível” (Winnicott, 1971, p. 15). Observa-se que conciliar a ambiência dos serviços de saúde pública com a predominância dos aspectos coletivos versus o atendimento adequado das necessidades individuais dos usuários mostra-se fundamental para o sucesso do tratamento e um desafio no cuidado em saúde mental infantojuvenil. 
Em alguns momentos, exigia-se de crianças e adolescentes a concentração em alguma atividade, sendo que o espaço físico em que se realizava privilegiava a dispersão e a utilização de recursos contrários à atividade ofertada aos pacientes. Tal fato demonstra a necessidade de o profissional adequar o uso do espaço ao objetivo da atividade proposta.

Os profissionais mencionavam dificuldades na elaboração de propostas de atividades como produto da estrutura física do CAPSi, por exemplo, a falta da piscina, integralmente utilizada na antiga casa em que funcionava o CAPSi, para o trabalho com crianças e adolescentes consideradas pelos profissionais como casos graves. Observou-se a falta de atividades específicas dirigidas a esses pacientes, pois, segundo relato dos profissionais, para o tratamento dessas crianças e adolescentes, a piscina mostrava a possibilidade de intervenção, organização corporal e estabelecimento de contato com pares.

Os profissionais, apesar de tentar estabelecer contato com esses pacientes considerados graves, apresentavam dificuldades em estabelecer intervenções que não utilizassem a piscina, modelo ao qual já estavam habituados a trabalhar e conseguiram resultados. Percebe-se que a complexidade do sofrimento da criança e do adolescente que chega ao serviço parece, em algumas situações, paralisar os profissionais, o que se mostra um complicador para o estabelecimento de uma comunicação.

O ambiente do CAPSi instigava a procura de outros espaços e instrumentos para a realização das atividades. Em certo dia, os adolescentes solicitaram aos profissionais uma quadra para jogarem bola, o que permitiu a saída de dentro do serviço para fazerem uso da quadra poliesportiva da Prefeitura Municipal no bairro, o que os possibilitou habitar, de forma saudável, outros espaços da cidade.

Os profissionais do CAPSi, ao possibilitarem aos adolescentes o uso de outros espaços, ampliam o espaço de seu mundo. Para Safra (1999), a vivência dos espaços arquitetônicos deriva dos sentidos da vivência do ser humano de seu próprio corpo, assim muros e paredes demarcam as fronteiras entre o dentro e o fora. $\mathrm{O}$ pedido de habitar outros espaços pode sinalizar o desenvolvimento da autonomia desses adolescentes, que se permitem descobrir outros espaços do mundo, o que só é possível, de acordo com o autor, quando se habita um mundo interno. Vale destacar também a proposta de atendimentos em espaços abertos da cidade, o que está de acordo com o redirecionamento à assistência em saúde mental a partir da Lei ${ }^{\circ} 10.216 / 2001$, que prevê serviços de base comunitária, visando à reinserção social do paciente em seu meio. 
As crianças usavam sua criatividade, adaptando o que o serviço oferecia para atender às suas necessidades. Em outra ocasião ainda, utilizaram uma lata de lixo como cesta de basquete.

Assim, verificou-se que, apesar das dificuldades salientadas pelos profissionais na elaboração de estratégias de intervenção complexas, como no caso dos pacientes considerados graves, a ambiência do CAPSi, em seus aspectos físicos, possibilitava o desenvolvimento de intervenções com qualidade, como descrito acima, em que foi acolhido o gesto dos pacientes, entendidos nesse estudo como gesto espontâneo na perspectiva de Winnicott, pois apresentava às crianças e aos adolescentes a possibilidade de criar a si mesmos e ao mundo.

Como acentua Winnicott (1971/1975), "É no brincar, e talvez apenas no brincar, que a criança ou o adulto fruem sua liberdade de criação" (p. 79). Avellar (2004) afirma que o brincar implica confiança no ambiente e que aspectos da singularidade da criança podem emergir como resultado da brincadeira. Dessa forma, ao fazer do cesto de lixo uma cesta de basquete, é possível que o ambiente do CAPSi tenha possibilitado às crianças brincarem por meio de um gesto criativo. Tal gesto possibilita a criação de um objeto de necessidade por meio de elementos existentes no ambiente.

Safra (1999) evidencia que apenas em um ambiente favorável o bebê, por meio de seu gesto, cria o mundo e, ao mesmo tempo, a si mesmo. "O gesto cria o objeto, mas cria concomitantemente o braço ou qualquer outra parte do corpo implicada na ação criativa. Abre-se também a própria capacidade de vir a conhecer o outro e o mundo" (Safra, 1999, p. 95). Observa-se como a segurança oferecida pelo serviço do CAPSi, em alguns momentos, permitiu o aparecimento do gesto espontâneo dos pacientes no sentido de criarem o que precisavam, o que possibilitou o relacionamento entre os pacientes, lidando com diferentes sentimentos e necessidades, tais como regras, ordem, raiva, solidariedade, acolhimento, ganhar e perder.

A ambiência do CAPSi, em seus aspectos físicos, como a estruturação adequada de um setting, pode proporcionar a reflexão sobre os materiais disponíveis para um tratamento terapêutico, bem como sobre o espaço em que este acontece, possibilitando o desenvolvimento de intervençôes com qualidade e o estabelecimento de uma comunicação entre profissional e paciente, ação essencial para a intervenção profissional capaz de fornecer tratamento adequado às crianças e aos adolescentes usuários de um serviço de saúde mental.

Pensar a ambiência em saúde mental possibilita refletir e criar formas de intervenção diante das novas diretrizes dessa assistência e da complexidade do sofrimento psíquico, de modo que os sujeitos envolvidos nesses processos 
possam se apropriar de novos espaços de acolhida e circulação que levem em consideração tempo, espaço, cultura e as relações sociais que permeiam um serviço de saúde, possibilitando ao paciente utilizar os símbolos do ambiente para significar sua vida.

\section{Considerações finais}

A saúde mental infantojuvenil, historicamente sob os domínios das áreas educacionais e assistenciais, rompe com paradigmas de cuidado quando se desloca para o campo da saúde. O CAPSi, marco da assistência às crianças e aos adolescentes no campo da saúde mental, também se destaca por ser um serviço que se constitui num momento em que a saúde mental se reorganiza e institui novas formas de cuidar.

Acessar o sofrimento de crianças e adolescentes apresenta particularidades que vão além do modelo assistencial estruturado para os adultos. $\mathrm{O}$ uso de objetos e meios lúdicos, como brinquedos, brincadeiras, histórias e produções de artes, mostram-se fundamentais para um trabalho que se propóe terapêutico, e isso somente é possível em um espaço que possibilite a criança brincar, comunicar e se organizar, em um ambiente que forneça elementos adequados para que a comunicação aconteça e os pacientes possam se apropriar de si, de lugares e de materiais que os possibilite acessar e expor seus sofrimentos, além da presença de um outro que acolha sua comunicação.

O CAPSi, por ser um novo serviço de saúde mental, rompe com o modelo asilar, possibilitando a adequação dos espaços às necessidades daquele que sofre, fornecendo um "ambiente suficientemente bom", facilitador do desenvolvimento humano. Verificou-se que, em alguns momentos, a ambiência do CAPSi, em seus elementos físicos, por si só possibilitava a comunicação das crianças e dos adolescentes de seus sofrimentos, necessitando que o profissional estivesse ali com sua escuta atenta, o que demonstrou a importância dos profissionais circularem pelos espaços do serviço para além de um cuidado coletivizado, tutelar e assistencial.

A descrição dos aspectos físicos da ambiência de um CAPSi possibilita ratificar que as constituições espaciais de um serviço de saúde influenciam suas práticas, pois o funcionamento do serviço em uma casa e não em uma instituição hospitalar marca que as intervenções podem ser mais acolhedoras, confortáveis e particularizadas. Os objetos disponíveis no ambiente podem facilitar ou dificultar o estabelecimento de vínculos entre usuários, promovendo ou impedindo o acesso e comunicação do sofrimento; além disso, a falta de materiais possibilita a discussão sobre a necessidade de novos elementos no serviço e instiga a 
criatividade dos usuários, fazendo-os buscar, de modo inventivo, o que falta, produzindo ricas oportunidades de intervenção.

A ambiência como um dos aspectos da política de humanização do SUS potencializa a compreensão das influências dos espaços de saúde em suas intervenções diárias e apresenta o desafio da constituição de espaços de saúde adequados às necessidades daquele que sofre. No processo de implantação da atenção psicossocial no campo da saúde mental infantojuvenil, pensar a ambiência possibilita a discussão da constituição dos serviços substitutivos ao modelo psiquiátrico asilar, rompendo com processos de adoecimento criados pelos processos de institucionalização. Entender que os objetos disponíveis no espaço assim como a organização das salas de atendimento, o universo social e cultural em que se insere o CAPSi, e a presença de um profissional com escuta e acolhimento estruturam um setting, moldura que marca tempo, espaço e presença, produz formas de cuidar, e traz o ganho de se construir ambientes favoráveis na atenção em saúde mental comprometidos com a qualidade dos espaços do cuidado, facilitando o desenvolvimento do trabalho terapêutico.

\section{Referências}

Avellar, L. Z. (2004). Jogando na análise de crianças: intervir-interpretar na abordagem winnicottiana. São Paulo: Casa do Psicólogo.

Avellar, L. Z. (2009). A pesquisa em psicologia clínica: reflexôes a partir da leitura da obra de Winnicott. Contextos Clínicos, 2 (1), 11-17.

Becker, H. S. (1997). Métodos de pesquisa em Ciências Sociais. São Paulo: Hucitec.

Benevides, R. \& Passos, E. (2005). Humanização na saúde: um novo modismo? Interface - Comunicação, Saúde e Educação, 17 (9), 389-394.

Brasil. Ministério da Saúde. Secretaria de Atenção à Saúde. Departamento de Ações Programáticas Estratégicas. (2005). Caminhos para uma política de saúde mental infanto-juvenil. Brasília: Ministério da Saúde.

Brasil. Ministério da Saúde. Secretaria de Atenção à Saúde. Núcleo Técnico da Política Nacional de Humanização. (2006a). Humaniza SUS: documento base para gestores e trabalhadores do SUS. Brasília: Ministério da Saúde. 
Brasil. Ministério da Saúde. Secretaria de Vigilância em Saúde. Secretaria de Atenção à Saúde. (2006b). Política nacional de promoção da saúde. Brasília: Ministério da Saúde.

Brasil. Ministério da Saúde. Secretaria de Atenção à Saúde. Núcleo Técnico da Política Nacional de Humanização. (2010). Ambiência. Brasília: Ministério da Saúde.

Cohen, S. C., Bodstein, R., Kligerman, D. C. \& Marcondes, W. B. (2007). Habitação saudável e ambientes favoráveis saúde como estratégia de promoção da saúde. Ciência \& Saúde Coletiva, 12 (1), 191-198.

D'Allones, C. R. (2004). O estudo de caso: da ilustração à convicção. In A. Giami \& M. Plaza (Orgs.). Os procedimentos clínicos nas ciências humanas: documentos, métodos, problemas. São Paulo: Casa do Psicólogo.

Demartini, J. (2007). Um olhar arquitetônico sobre centros de atenção psicossocial infantil: o caso do CAPSi de Cuiabá. (Dissertação de mestrado). Universidade Federal de Santa Catarina, Programa de Pós-Graduação em Arquitetura e Urbanismo, Florianópolis.

Hisada, S. (2000). A intervenção por meio do manejo do setting como facilitador de mudança psíquica no processo psicoterápico. (Tese de doutorado). Universidade de São Paulo, Instituto de Psicologia da Universidade de São Paulo, São Paulo.

Khan, M. M. R. (1984). Vicissitudes do ser, do conhecer e do experimentar na situação terapêutica. In M. M. R. Khan, Psicanálise: teoria, técnica e casos clínicos. (pp. 247-265). Rio de Janeiro: Francisco Alves. (Publicado Originalmente em 1969).

Lei no 10.216, de 6 de abril de 2001. (2001, 6 de abril). Dispõe sobre a proteção e os direitos das pessoas portadoras de transtornos mentais e redireciona o modelo assistencial em saúde mental. Diário Oficial da União, Brasília. Recuperado a partir de http://www.planalto.gov.br/ccivil_03/leis/leis_2001/ 110216.htm.

Minayo, M. C. de S. (1994). Pesquisa Social: teoria, método e criatividade. Petrópolis: Vozes.

Portaria GM 336, de 19 de fevereiro de 2002. (2002, 19 de fevereiro). Estabelece as modalidades de serviços dos Centros de Atenção Psicossocial: CAPS I, CAPS II, CAPS III, CAPS i II e CAPS ad II. Brasília: Ministério da Saúde. 
Recuperado a partir de http://bvsms.saude.gov.br/bvs/saudelegis/gm/2002/ prt0336_19_02_2002.html.

Resolução no 196, de 10 de outubro de 1996. (1996, 10 outubro). Diretrizes e normas regulamentadoras de pesquisas envolvendo seres humanos. Brasília: Ministério da Saúde, Conselho Nacional de Saúde.

Safra, G. (1999). A face estética do self: teoria e clínica. São Paulo: Unimarco.

Souza, A. M. O. (2003). Loucura em cena: a "Ambiência" como espaço informal de tratamento em um Centro de Atenção Psicossocial. (Tese de doutorado). Pontifícia Universidade Católica de São Paulo, Programa de Pós-graduação em Psicologia da Aprendizagem, do Desenvolvimento e da Personalidade, São Paulo.

Turato, E. R. (2003). Tratado da metodologia da pesquisa clínico-qualitativa: construção teórico-epistemológica, discussão comparada e aplicação nas áreas da saúde e humanas. Petrópolis: Vozes.

Winnicott, D. W. (2000). Ansiedade associada à insegurança. In D. W. Winnicott, Da pediatria à psicanálise: obras escolhidas. (pp. 163-167). Rio de Janeiro: Imago (Publicado originalmente em 1952).

Winnicott, D. W. (2000). Aspectos clínicos e metapsicológicos da regressão no contexto analítico. In: D. W. Winnicott, Da pediatria à psicanálise: obras escolhidas. (pp. 375-392). Rio de Janeiro: Imago. (Publicado originalmente em 1954).

Winnicott, D. W. (2000). A preocupação materna primária. In D. W. Winnicott, Da pediatria à psicanálise: obras escolhidas. (pp. 399-405). Rio de Janeiro: Imago. (Publicado originalmente em 1956).

Winnicott, D. W. (1983). A integração do ego no desenvolvimento da criança. In D. W. Winnicott, O ambiente e os processos de maturação: estudos sobre a teoria do desenvolvimento emocional. (pp. 55-61). Porto Alegre: Artmed. (Publicado originalmente em 1962).

Winnicott, D. W. (1994). A importância do setting no encontro com a regressão na psicanálise. In: C. Winnicott, R. Shepherd \& M. Davis (Orgs.), Exploraçōes psicanaliticas. (pp. 77-81). Porto Alegre: Artes Médicas Sul. (Publicado originalmente em 1964).

Winnicott, D. W. (1984). Consultas terapêuticas em psiquiatria infantil. Rio de Janeiro: Imago. (Publicado originalmente em 1971). 
Winnicott, D. W. (1975). O brincar e a realidade. Rio de Janeiro: Imago. (Publicado originalmente em 1971). 